\title{
Risk of Zika virus-associated birth defects in congenital confirmed cases in the Brazilian Amazon
}

\author{
Consuelo S. de Oliveira ${ }^{1}$, Haroldo José de Matos ${ }^{1}$, Francisco Luzio de Paula Ramos ${ }^{1}$, Ana Yece das \\ N. Pinto ${ }^{1}$, Priscila Nathyelly dos S. Graim ${ }^{2}$, Vivianne de Paula R. Guimarães ${ }^{2}$, Luna Thaís S. Gomes ${ }^{1}$, \\ Emilene M. F. Serra ${ }^{1}$, Ana Cecília Cruz ${ }^{1}$, Alessandra Leal', Daniele F. Henriques ${ }^{1}$, Juliana A. Lima ${ }^{1}$, \\ Maura V. Anjos ${ }^{1}$, Eliana V. Pinto ${ }^{1}$, Alana W. de Souza ${ }^{1}$ and Pedro Fernando da C. Vasconcelos ${ }^{1}$
}

Suggested citation Oliveira CS, Matos HJ, Ramos FLP, Pinto AYN, Graim PNS, Guimarães VPR, et al. Risk of zika virus-associated birth defects in congenital confirmed cases in the Brazilian Amazon. Rev Panam Salud Publica. 2020;44:e116. https://doi.org/10.26633. RPSP.2020.116

ABSTRACT

Objective. To establish the risk of microcephaly in neonates born to women infected with ZIKV during pregnancy.

Methods. A cohort of laboratory-confirmed ZIKV cases of congenital infections (109 mothers infected during pregnancy and 101 newborns) among 308 suspect cases was followed in Belem, Pará, Brazil, from October 2015 to December 2017.

Results. A microcephaly risk of $1.98 \%(95 \% \mathrm{Cl} 0.54-6.93 \%)$ was found, or 2 cases among the 101 neonates infected with ZIKV during pregnancy. $72 \%$ of the pregnant women had ZIKV infection confirmed by RT-qPCR during gestation.

Conclusions. Results showed a low incidence of ZIKV-associated birth defects, stillbirth, and miscarriage, which contrasts with previous studies in other Brazilian regions. Previous exposure to yellow fever vaccine and/ or multiserotype DENV infection could be implicated in the protection from ZIKV congenital infection.

Keywords

Zika virus infection; microcephaly; pregnancy complications, infectious; Brazil.

Zika virus (ZIKV) affected Brazil and the Americas in 20152016 leaving an enormous burden of disease sequelae, mainly affecting the neural tube development and causing microcephaly in the newborn when infection occurred in pregnant women, particularly in the first trimester of gestation characterizing the zika congenital syndrome (1-3). A previous outbreak of the disease in French Polynesia had already shown the central nervous system (CNS) involvement, with occurrence of Guillain-Barré syndrome but also an unexpected high number of microcephaly cases in newborns following infections of pregnant women (4).

Although the first cases of microcephaly observed in Brazil were detected in the Northeast region, the epidemic spread to all geographical regions and cases of microcephaly were diagnosed in all regions too. Based on notified cases of microcephaly in Brazil, the estimated risk of microcephaly associated with ZIKV (assuming 10\% of infected women during pregnancy) varied across the regions from 0.16 to $17.1 \%$ (1). A number of factors seem to affect these contrasting results, and the different estimates of risk were also related to different criteria for defining infection in pregnant women. One clear difficulty is defining infection based on serology alone due to cross-reactivity in patients with history of past or recent flavivirus infections, in particular dengue virus. In fact, in most Brazilian studies these criteria prevailed (1). It was already shown that in RT-qPCR confirmed cases the risk of microcephaly alone was $5.8 \%$ in a study

\footnotetext{
Instituto Evandro Chagas, Ananindeua, Brazil $₫$ Haroldo José de Matos, haroldodematos@gmail.com
} 
of 546 pregnant women in the American French territories (5). It was also shown a $7.0 \%$ of overall risk of evident neurologic and ocular defects at birth, possibly associated with ZIKV infection. Despite these findings, it is possible that a reliable estimate of risk of microcephaly in newborns after ZIKV infection of pregnant women in Brazil remains imprecise, especially due to different methodologies and spatial discrepancies (1-3).

The main objective of this study was to establish the risk of microcephaly in neonates born to women infected with ZIKV during pregnancy.

\section{METHODS}

\section{Population}

A sample of 308 pregnant women who were referred to Evandro Chagas Institute, a national reference center for arboviral diseases research, was followed-up in the clinical setting of the Institute. The Institute is located in the metropolitan area of Belem, the capital of Pará state, in the east Amazon region.

\section{Study design}

A longitudinal study was performed of a cohort of pregnant women with clinical suspicion of acute disease due to ZIKV, independent of gestational age, with specific molecular and serology laboratory confirmation for ZIKV. All patients were residing in the metropolitan region of Belem, Pará, Brazil, and were recruited from October 2015 to December 2017. The pregnant women were followed by physicians at the Unified Medical Care Service (SOAMU) of the Evandro Chagas Institute up to delivery, and then for two additional years. The women enrolled in the study were evaluated every month by the same physician who initiated the follow-up, in two settings of the Evandro Chagas Institute (one in Belem and another in Ananindeua, a nearby city in the metropolitan region of Belem). Ultrasound exams were performed in at least each trimester of the pregnancy.

In order to identify the causal infectious agents, blood/serum was collected for identification of ZIKV and other infectious agents, including Chikungunya virus (CHIKV); dengue virus (DENV); cytomegalovirus (CMV); rubella virus (RUBV); Toxoplasma gondii; Trypanosoma cruzi; Treponema pallidum; human immunodeficiency virus (HIV); hepatitis virus A (HAV), B (HBV) and C (HCV); and parvovirus B19 (PV-B19). Samples were analyzed at the Institute's laboratories. For arbovirus study, blood/serum samples were collected up to the fifth day after onset of symptoms and sent to the Molecular Biology Laboratory (for quantitative real-time polymerase chain reaction, RT-qPCR), the gold standard test for acute ZIKV disease. In the samples obtained after seven days of disease onset, serology was performed by an in-house IgM-ELISA in accordance with the US. Center for Disease Control (CDC) laboratory diagnosis recommendations. In cases with inconclusive results due to cross reactivity, plaque reduction neutralization tests (PRNT) were performed according to CDC guidelines for laboratory diagnosis of ZIKV disease (5).

\section{Inclusion criteria}

Pregnant women with rash and at least two of the following symptoms were included: fever, arthralgia, conjunctival erythema or articular edema (according to the case definition of acute ZIKV disease of the Ministry of Health in Brazil) who lived in the metropolitan area of Belem and signed the written informed consent to participate in the study. Exanthema was present in all patients under study, with a maculopapular pattern, itching and an average duration of 4 days, similar to the rash due to ZIKV infection observed all over Brazil.

\section{Exclusion criteria}

Pregnant women referred to the Institute who were symptomatic for ZIKV infection but did not live in the metropolitan area of Belem or were not willing to sign the written informed consent to participate in the study. Women with previous infection with HIV, or with coinfection with toxoplasmosis, CMV or syphilis were also excluded.

\section{Statistical methods}

One-sample test for binomial proportion, normal-theory method or Fisher exact test were performed to estimate 95\% confidence intervals. Statistical test for proportion to differ from 0.5 was also performed, using Open Epi program $(6,7)$.

\section{Ethics}

This study was approved by the ethics committee of the Evandro Chagas Institute. All participants were voluntary and signed an informed consente form; confidentiality of data was granted to all participants.

\section{RESULTS}

From October 2015 to December 2017, 308 symptomatic pregnant women were reported as suspect cases of ZIKV disease at the Evandro Chagas Institute in Belem and samples were collected for testing for ZIKV and other arboviral diseases, as well as other infectious agents associated with congenital disease. The period of this study represented the timing of highest risk for ZIKV infection in Pará state (Figure 1).

ZIKV recent infections were confirmed in 134 pregnant women. From these, 109 were included in clinical and

FIGURE 1. Temporal distribution of ZIKV pregnant women suspected cases, October 2015 to December 2016.

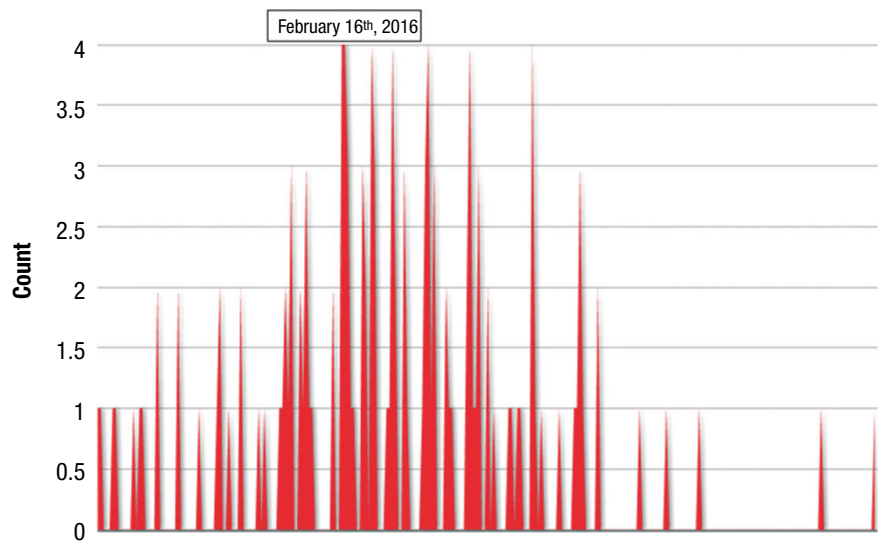


FIGURE 2. Study population of the 109 pregnant women with laboratory-confirmed ZIKV recent infection who were followed-up

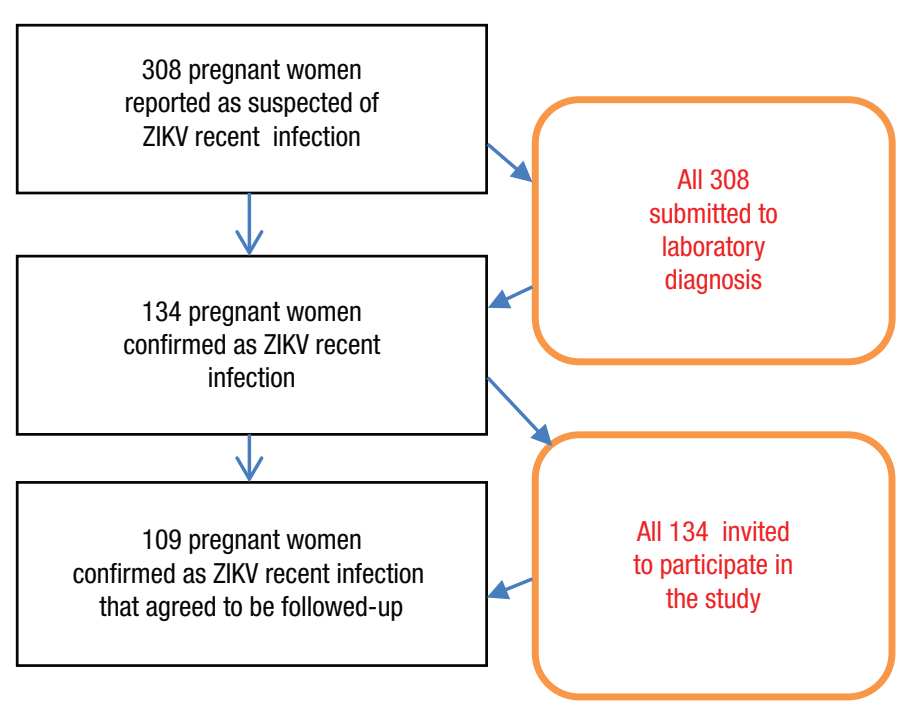

laboratorial follow-up (Figure 2); 72\% of the pregnant women had confirmed ZIKV infection by RT-qPCR during gestation.

The 109 pregnant women who were followed gave birth to 101 live born infants. There were 7 abortions and 1 stillbirth. Premature labor was confirmed in 2 cases, and there were 2 cases of deaths immediately after delivery.

Two neonates were classified as microcephaly according to the curves of fetal growth used by the World Health Organization (WHO), i.e., $1.98 \%$ (95\% CI $0.54-6.93 \%)$ or 2 cases of microcephaly in the cohort of 101 neonates.

In $85(84 \%)$ cases, the confirmation criteria used was RT-qPCR (CDC gold standard); 18 (17.8\%) cases were IgM-ELISA positive; $3(3 \%)$ cases were RT-qPCR and IgM-ELISA positive; and $2(2 \%)$ cases were confirmed by PRNT. IgM-ELISA and PRNT50\% with titers above 20 were also used as laboratory confirmation criteria, following CDC's laboratory diagnosis recommendations for ZIKV infection. Considering only the 85 RT-qPCR-confirmed cases, the estimated rate of microcephaly was 2.35 (95\% CI 0.64-8.17).

General information and clinical findings of the 109 confirmed cases of ZIKV-infected pregnant women are shown in Table 1. Microcephaly was confirmed in two neonates, one of them diagnosed immediately after delivery; the other case had a normal head circumference at birth, but six months later microcephaly was confirmed and associated with skull calcification at the CT scan. The baby with microcephaly was a girl born at term with a birth weight of $3.168 \mathrm{~kg}$, but a cephalic perimeter of $29 \mathrm{~cm}$, below the cutoff according to WHO. None of the pregnant women who were followed-up had a history of diabetes mellitus or hypertension.

Besides microcephaly, neonates showed additional clinical findings including one case each of congenital cataract, neonatal jaundice and hypoglycemia after delivery. There were 11 cases of preterm delivery apart from the mentioned 2 cases of stillbirth and 6 cases of miscarriage. Also, there were 2 cases of low birth weight.

IgM-ELISA tests for CHIKV, DENV, CMV and RUBV were also performed. Despite inconclusive IgM serology results for
TABLE 1. Characteristics of pregnant women with laboratoryconfirmed ZIKV infection in the Pará state

\begin{tabular}{|c|c|c|c|}
\hline \multirow[t]{2}{*}{$\begin{array}{l}\text { General and clinical } \\
\text { characteristics }\end{array}$} & \multirow[b]{2}{*}{$\mathrm{N}$} & \multirow[b]{2}{*}{$\%$} & \multirow[b]{2}{*}{$\mathrm{Cl} 95 \%{ }^{*}$} \\
\hline & & & \\
\hline Age (years) & 109 & & \\
\hline$<20$ & 9 & 8.2 & $3.7-15.6$ \\
\hline $20-29$ & 52 & 47.7 & $36.9-56.2$ \\
\hline $30-39$ & 43 & 39.5 & $31.4-51.3$ \\
\hline$\geq 40$ & 5 & 4.6 & $1.8-11.8$ \\
\hline Ethnicity & 109 & & \\
\hline White & 30 & 27.5 & $21.4-40.1$ \\
\hline Black & 8 & 7.4 & 2.4-13.1 \\
\hline Mixed & 71 & 65.1 & $53.7-73.2$ \\
\hline Marital status & 109 & & \\
\hline Single & 33 & 30.3 & $21.4-40.1$ \\
\hline Married & 39 & 35.8 & $26.8-46.2$ \\
\hline Stable union & 36 & 33.0 & 23.2242 .1 \\
\hline Divorced & 1 & 0.9 & $0.05-6.2$ \\
\hline Education (years) & 109 & & \\
\hline $0-4$ & 8 & 7.3 & $2.4-13.1$ \\
\hline $5-9$ & 59 & 54.1 & $43.7-63.9$ \\
\hline $10-14$ & 34 & 31.2 & $22.3-41.1$ \\
\hline$>15$ & 8 & 7.4 & $3.7-15.6$ \\
\hline Number of previous pregnancies & 109 & & \\
\hline None & 42 & 38.5 & $29.9-47.9$ \\
\hline One & 37 & 33.9 & $25.7-43.2$ \\
\hline Two or more & 30 & 27.5 & $20.0-36.6$ \\
\hline Outcomes & 109 & & \\
\hline Born alive & 101 & 92.7 & $88.9-98.3$ \\
\hline Abortions & 7 & 6.4 & $0.2-6.9$ \\
\hline Fetal death & 1 & 0.9 & $0.6-8.6$ \\
\hline $\begin{array}{l}\text { CNS malformation } \\
\text { (among live born) }\end{array}$ & 101 & & \\
\hline No malformation & 99 & 98.1 & $92.2-99.6$ \\
\hline Microcephaly & 2 & 1.9 & $0.3-7.7$ \\
\hline Gestational age of infection & 109 & & \\
\hline First trimester & 21 & 19.3 & $12.1-22.3$ \\
\hline Second trimester & 59 & 54.1 & $44.7-64.8$ \\
\hline Third trimester & 29 & 26.6 & $17.9-35.9$ \\
\hline Symptoms & 109 & & \\
\hline Rash & 109 & 100.0 & $96.4-100$ \\
\hline Pruritus & 88 & 80.7 & $78.0-92.2$ \\
\hline Arthralgia & 78 & 71.6 & $67.0-84.3$ \\
\hline Myalgia & 62 & 56.9 & $50.6-70.3$ \\
\hline Retroorbital pain & 57 & 52.3 & $45.7-65.7$ \\
\hline Joint edema & 53 & 48.7 & $41.8-61.9$ \\
\hline Lymphadenopathy & 51 & 46.8 & $39.9-60.0$ \\
\hline Fever & 45 & 41.3 & $34.2-54.2$ \\
\hline Conjunctival hyperemia & 11 & 10.1 & $5.5-18.4$ \\
\hline
\end{tabular}

${ }^{*}$ Fisher's exact test.

Source: data from the authors' study.

DENV, all the other results were non-reactive. Also, positive reactions to syphilis, HIV or viral hepatitis A, B and C were not detected. 
The time of the ZIKV infection during pregnancy ranged from 10 to 36 weeks of gestation. Both cases of microcephaly had an estimated time of infection of 12 weeks. The expected frequency of all CNS malformations, including microcephaly, in Pará state before 2015 was 0.6 per 1000 live births (Datasus, 2014).

\section{DISCUSSION}

This study estimated $1.98 \%$ of microcephaly in live-born children from symptomatic, laboratory-confirmed ZIKV-infected pregnant women with $72 \%$ of RT-PCR confirmed ZIKV infection. The abortion rate found was $2.94 \%$ (95\% CI 0.61-8.35). One fetal death and one neonate death were found.

These results were similar to those of previously published studies of $5 \%$ with ZIKV-associated birth defects in pregnancy outcomes observed in US territories $(8,9)$, and of $5.8 \%$ of microcephaly found in the study of pregnancy outcomes in French territories in the Americas in fetuses of women infected by ZIKV during gestation (8). Exanthema was present in all patients in the study with a maculopapular pattern, itching and an average duration of 4 days, similar to the rash due to ZIKV infection observed in other regions of Brazil. However, the results are different from those of studies in other Brazilian regions, especially from the Northeast region and Rio de Janeiro state (3); these spatial differences are a matter of debate, and possible causes or hypotheses are not consensual. Data from the Microcephaly Reporting System in Brazil show great prevalence variation of microcephaly in diverse regions of Brazil. In Pará state, of which Belem is the capital, the rate was $0.45 / 10000$ live births, whereas in Pernambuco - where the first cases of microcephaly were studied- it was 4.87/10000 live births in 2016 (10).

It has been hypothesized that in regions where yellow fever vaccine is mandatory, the incidence of CNS defects was lower than in regions where it was not recommended, and this could explain the spatial discrepancies observed in CNS malformations associated with ZIKV infection in pregnant women in different regions (11). In accordance with this hypothesis, it was shown that individuals that were immunized with yellow fever vaccine developed a $\mathrm{ZIKV}$-specific $\mathrm{CD} 8^{+} \mathrm{T}$ cells response, which are important for the clearance of virus-infected cells (12). A recent study on adolescents in the metropolitan area of Belem showed a high yellow fever vaccination coverage $(88 \%)$, whereas in most states from the Northeastern region of Brazil yellow fever vaccination was not recommended in 2016 (13). Additional specific studies focusing on this variable are necessary to clarify this hypothesis.

Previous DENV infection could also provide a clue to these disparities, since epidemics with all DENV serotypes have occurred throughout Brazil in the last 20 years. In fact, multitypic DENV infections could be a source of great variation in immune response to ZIKV. In a 2019 article by Pedroso et al. (14), the authors suggest that due to previous contact of pregnant women with different DENV serotypes, ZIKV may not cause congenital zika syndrome, but rather the DENV antibodies could protect against its occurrence. Nevertheless, in Brazil in 2016 the incidence rate of dengue was lower in Pará state (56 in $10^{5}$ ) than that in Pernambuco $\left(498\right.$ in $\left.10^{5}\right)$, in an opposite direction of the incidence of congenital zika syndrome in these states (10).

In this study, $72 \%$ of the women had confirmed ZIKV infection by RT-qPCR during gestation. Few studies in the literature, particularly from Brazil, had a higher proportion of confirmed pregnant women using a gold standard test. The results in this study are comparable to those from the French Polynesia study during the 2013 epidemics (4), but significantly lower than those observed in other regions of Brazil such as the Northeast -which presented a higher incidence of birth defects (5) -, but birth defects can be underestimated because only defects evident at birth have been measured. A cohort of the children exposed to confirmed ZIKV infection during gestation is being followed-up. In contrast to Brazilian studies from the Northeastern region a report from a Mexican general hospital has shown no malformation at birth (15). Data from the Pan American Health Organization published in 2017 also show that incidence of congenital zika syndrome had a heterogeneous distribution in the countries of the Americas, Brazil being the country with the highest incidence $(16,17)$.

This study presented some limitations, including the lack of analysis of fetal/placental tissue from abortion and stillbirth cases. Accurate data from ultrasound and other imaging techniques were also not included. The complete picture of congenital zika syndrome is also lacking in this study since data from a cohort of children born to ZIKV infected pregnant women are still being analyzed. Finally, no accurate information on previous yellow fever vaccination or previous episode of dengue fever could be confirmed.

Considering that microcephaly is only one clinical finding in the congenital zika syndrome spectrum and the possibility of a new wave of ZIKV epidemics in the coming years, the development of a specific zika vaccine is mandatory in order to protect against severe congenital disease caused by ZIKV. Fortunately, it is expected in the coming years, bringing hope that an efficacious prophylactic measure will soon be available (18).

In conclusion, the results of the cohort presented here showed a microcephaly risk of $1.98 \%$ (95\% CI $0.54-6.93 \%)$, or 2 cases of microcephaly among 101 born alive children. It is also important to emphasize that a cohort of children intra-utero exposed to ZIKV should be followed-up to detect other unfavorable outcomes which could be apparent during development, as occurred in one case from this study diagnosed as a case of microcephaly some weeks after birth.

Authors' contributions. CSO and HJM planned the study, cared for the patients and drafted the manuscript; FLPR and AYNP contributed to the care and follow-up of the patients; PNSG, VPRG, LTSG, EMFS, ACC, AL, DFH, JAL, MVA, EVP, AWS performed all laboratory tests; PFCV planned the study and helped to draft the paper. All authors revised the final version for publication.

Acknowledgments. To Dr. Carlos Alberto Marques de Carvalho for his excellent contribution to the draft of the article.

\section{Conflicts of interest. None declared.}

Funding. Financial support provided by the Evandro Chagas Institute.

Disclaimer. The views and opinions in the manuscript are the authors' and may not necessarily reflect the opinion or policy of the RPSP/PAJPH and/or PAHO. 


\section{REFERENCES}

1. Brasil. Ministério da Saúde. Secretaria de Vigilância em Saúde Vírus Zika no Brasil: a resposta do SUS. Ministério da Saúde, Secretaria de Vigilância em Saúde. - Brasília: Ministério da Saúde; 2017. p 81-88.

2. Reynolds MR, Jones AM, Petersen EE, et al. Vital signs: update on Zika virus-associated birth defects and evaluation of all U.S. infants with congenital Zika virus exposure - U.S. Zika Pregnancy Registry, 2016. MMWR Morb Mortal Wkly Rep. 2017; 66: 366-73.

3. Jaenish T; Rosenberger KD; Brito C; Brady O; Brasil P; Marques ET. Risk of microcephaly after Zika vírus infection in Brazil, 2015 t0 2016. Bull World Health Organ. 2017;95(3):191-198.

4. Cauchemez S, Besnard M, Bonpard P, Dub T, Guillemette-Artur, Eyro lle-Guignot D, et al. Association between Zika virus and microcephaly in French Polynesia, 2013-2015: a retrospective study. Lancet. 2016;87(10033): 2125-2132.

5. Sharp TM, Fischer M, Muñoz-Jordán JL, et al. Dengue and Zika Virus Diagnostic Testing for Patients with a Clinically Compatible Illness and Risk for Infection with Both Viruses. MMWR Recomm Rep. 2019;68(No. RR-1):1-10. DOI: http://dx.doi.org/10.15585/ mmwr.rr6801a1external icon.

6. Dean A. Epi Info, version 7.2.2.6. CDC: Atlanta; 2018.

7. Kevin M. Sullivan, Emory University based on code from John C. Pezzullo. www.openepi.com.

8. Hoen B, Schaub B, Funk AL, Ardillon V, Boullard M, et al. Pregnancy outcomes after ZIKV infection in French territories in the Americas. N Eng J Med. 2018;378:985-994.

9. Shapiro-Mendoza CK, Rice ME, Galang RR, et al. Pregnancy outcomes after maternal Zika virus infection during pregnancy - U.S. territories, January 1, 2016-April 25, 2017. MMWR Morb Mortal Wkly Rep. 2017; 66: 615-21.

10. Garcia LP. Epidemia do vírus Zika e microcefalia no Brasil: emergência, evolução e enfrentamento. Instituto de Pesquisa Econômica Aplicada (IPEA). Ministério do Planejamento, Desenvolvimento e Gestão, Brasil; 2018.

11. Cavalcanti LPG, Tauil PL, Alencar CH, Oliveira W, Teixeira MM, Heukelbach J. Zika virus infection, associated microcephaly, and low yellow fever vaccination coverage in Brasil: Is there a causal link? J Infect Dev Ctries. 2016;10(6):563-6. doi: 10.3855/ jidc. 8875 .

12. Blom K, Sandberg JT, Loré K, Ljunggren HG. Prospects for induction of CD8 T cell-mediated immunity to Zika virus infection by yellow fever virus vaccination. J Int Medicine. 2017;282:206-208. doi: 10.1111/joim.12638.

13. Lemos EO, Pedroda DR, Raniére PSG et al. Avaliaçao do cumprimento do calendário de vacinaçao dos adolescentes de uma escola municipal. Revista Adolescência e Saúde. 2020; www.adolescenciaesaude.com

14. Pedroso C, Fischer C, Feldman M, Sarno M, Luz E, Moreira-Souto A et al. Cross-protection of Dengue vírus infection against Congenital Zika Syndrome, Northeastern Brazil. Emerg Infec Dis. 2019;25(8):1485-1493.

15. del Carpio-Orantes L, Rosas-Lozano AL and García-Méndez S. Zika virus infection in pregnant women in a General Hospital of Veracruz, Mexico. J Matern Fetal Neonatal Med. 2019:1-5 DOI: 10.1080/ 14767058.2019.1582627.

16. Secretaria de Vigilância em Saúde/Ministério da Saúde. Boletim Epidemiológico. 2017;48(3):1-10.

17. Pan American Health Organization. Zika suspected and confirmed cases reported by countries and terrotories in the Americas cumulative cases, 2015-2017. Washigton, DC.: PAHO/WHO; 2018.

18. Shan C, Muruato A, Nunes B, Luo H, Xie X, Medeiros DB et al. A live-attenuated Zika virus vaccine candidate induces sterilizing immunity in mouse models. Nature Medicine. 2017;23:763.

Manuscript received on February 5 2020; revised version accepted for publication on June 22020.

\section{Riesgo de malformaciones congénitas asociadas al virus del Zika en casos confirmados en la Amazonia brasileña}

RESUMEN Objetivo. Establecer el riesgo de microcefalia en los recién nacidos de mujeres infectadas con ZIKV durante el embarazo.

Métodos. Se siguió a una cohorte de casos con infección congénita por ZIKV confirmada por laboratorio (109 madres infectadas durante el embarazo, 101 recién nacidos) conformada a partir de 308 casos sospechosos en Belem, Pará, Brasil, de octubre de 2015 a diciembre de 2017.

Resultados. Se encontró un riesgo de microcefalia de 1,98\% (IC95\% 0,54-6,93\%), o 2 casos entre los 101 neonatos infectados con ZIKV durante el embarazo. En el 72\% de las mujeres embarazadas se confirmó mediante RT-qPCR la infección por ZIKV durante la gestación.

Conclusiones. Los resultados mostraron una baja incidencia de malformaciones congénitas, mortinatos y abortos asociados al ZIKV, lo que contrasta con estudios anteriores de otras regiones de Brasil. La exposición previa a la vacuna contra la fiebre amarilla o la infección previa por varios serotipos de virus del dengue podrían estar implicados en la protección contra la infección congénita por ZIKV.

Palabras clave Infección por el virus Zika; microcefalia; complicaciones infecciosas del embarazo; Brasil. 